\title{
The prevalence of schistosomiasis in school-aged children as an appropriate indicator of its prevalence in the community
}

\author{
Ana Paula Braz Pereira', Tereza Cristina Favre ${ }^{1 /}{ }^{+}$, Aline Favre Galvão', Lilian Beck', \\ Constança Simões Barbosa², Otávio Sarmento Pieri'
}

'Laboratório de Ecoepidemiologia e Controle da Esquistossomose e Geohelmintoses, Instituto Oswaldo Cruz-Fiocruz, Av. Brasil 4365, 21045-900 Rio de Janeiro, RJ, Brasil ²Departamento de Parasitologia, Instituto Aggeu Magalhães-Fiocruz, Recife, PE, Brasil

School-aged children (6-15 years) from the endemic area of Pernambuco were evaluated both as a target group for and an indicator of schistosomiasis control in the community. Parasitological data were drawn from baseline stool surveys of whole populations that were obtained to diagnose Schistosoma mansoni infection. Nineteen representative localities were selected for assessing the prevalence of schistosomiasis among individuals in the following age groups: 0-5, 6-15, 16-25, 26-40 and 41-80 years. For each locality, the prevalence in each age group was compared to that of the overall population using contingency table analysis. To select a reference group, the operational difficulties of conducting residential surveys were considered. School-aged children may be considered to be the group of choice as the reference group for the overall population for the following reasons: (i) the prevalence of schistosomiasis in this age group had the highest correlation with the prevalence in the overall population $(r=$ 0.967), (ii) this age group is particularly vulnerable to infection and plays an important role in parasite transmission and (iii) school-aged children are the main target of the World Health Organization in terms of helminth control. The Schistosomiasis Control Program should consider school-aged children both as a reference group for assessing the need for intervention at the community level and as a target group for integrated health care actions of the Unified Health System that are focused on high-risk groups.

Key words: schistosomiasis control - school-aged children - reference group - target group - Pernambuco - Brazil

In Brazil, schistosomiasis transmission occurs in a vast endemic area that is located mainly in the Northeastern and Southeastern Regions of the country. However, additional isolated foci have been identified in several states and cases of the disease have been detected nationwide. In Northeastern Brazil, the state of Pernambuco (PE) is among those with the highest prevalence rates of infection (Coura \& Amaral 2004) despite successive control campaigns that have been carried out by the Ministry of Health (MS). In addition to persistent infection in many rural municipalities of the rainforest zone, new transmission sites and cases of acute infection have appeared in the coastal zone, particularly in beach localities that have intense tourist activity. This indicates a change in the epidemiological profile of schistosomiasis in PE. In rural areas, the disease continues to manifest itself predominantly in the chronic form and primarily affects low-income individuals, whereas along the coast, most cases are acute cases affecting individuals in the middle/high-income classes (Barbosa et al. 2001, Favre et al. 2007).

By 1999, the Schistosomiasis Control Program (PCE) was decentralised in PE and the municipalities became responsible for surveillance and control actions within the Unified Health System (SUS) through the Municipal Co-

\footnotetext{
+ Corresponding author: tfavre@ioc.fiocruz.br

Received 13 January 2009

Accepted 9 October 2009
}

ordination of Endemic Diseases division. The MS (with the support of the State Secretary of Health) is now responsible for the creation of guidelines, coordination and monitoring of municipalities' activities regarding schistosomiasis control (Favre et al. 2006a). The following guidelines have been established for endemic areas: (i) identification of carriers through regular, community-based stool surveys at the locality level carried out by Agents for the Control of Endemic Diseases and (ii) treatment of individuals with eggs identified in their stool by Basic Attention/Family Health (AB/SF) teams in Basic Health Units (UBS). After the initial screening occurs, the MS recommends biennial evaluations with a priority placed on control actions in localities with prevalence rates greater than 5\% (MS 2007).

In the endemic area of PE, the guidelines established by the MS have not been effectively followed by the PCESUS, mainly due to financial and personnel constraints (Favre et al. 2006a). Data made available by the Secretary of Health Surveillance (SVS) of the MS through the Computerized System of the PCE (MS 2008) reveal that only $24 \%$ of the population of 3.4 million received coverage from the PCE-SUS between 2001-2007. Therefore, it is important to assess whether or not it is within the capacity of the municipalities to raise coverage to an acceptable level. It is probable that the municipal health organisations are already working at maximum capacity, which would make it unfeasible to carry out biennial parasitological surveys of the entire population and provide treatment to all carriers. If this is the case, an alternative strategy should be proposed so as to allow municipalities to carry out schistosomiasis surveillance and control actions within their capacity (Favre et al. 2006a). 
In 1998, the World Health Organization (WHO) formulated an operational model to guide national, regional and local health authorities with regard to the planning and execution of schistosomiasis surveillance and control programs at the community level (Montresor et al. 1998). This model was later refined (Montresor et al. 2002) and incorporated into the recommendations of the Expert Committee of the WHO (WHO 2002) that were focused on endemic countries that were having difficulty attaining their goals. The WHO itself suggested that the model be adapted to the epidemiological reality of each country or region.

The WHO model recommends the use of school-aged children both for baseline and follow-up surveys, which would allow for the assessment of the ongoing prevalence of schistosomiasis and the need for intervention in the community as a whole. The WHO model also provides guidance regarding the application of control measures and the monitoring of their impact on the communities in question (Montresor et al. 2002). To this end, three classes of schistosomiasis prevalence were suggested: low (below $10 \%$ ), moderate (between 10-50\%) and high (above 50\%).

However, the WHO model may not be directly applicable to the reality of PE for two main reasons: (i) health actions by the PCE-SUS are currently implemented in the UBS and not in schools and (ii) the age group of 6-15 years may not truly reflect the prevalence of the disease and the need for intervention in the community as a whole in endemic municipalities. Therefore, this study sought to determine whether or not school-aged children constitute an effective reference group to assess the ongoing schistosomiasis prevalence in the overall community, to guide the selection of control strategies and to monitor the impact of these control strategies in the endemic area of PE.

\section{PATIENTS, MATERIALS AND METHODS}

Selection of municipalities for the study - The selection of localities for this study was carried out in order to include the two current epidemiological profiles of the disease in PE. Thus, six localities representative of the coastal zone and 13 representative of the rainforest zone, located in a total of six different municipalities, were selected for the analysis of schistosomiasis prevalence in all age groups. Information regarding the numbers of residents and examined persons in each municipality, the mean age of individuals in each municipality and the dates on which the baseline surveys were conducted in the 19 localities are summarised in Table I.

Sources of parasitological data - The parasitological data were taken from previous studies involving population surveys that took place in various localities in the municipalities of São Lourenço da Mata (Favre 1999, Beck et al. 2001, Zani et al. 2004), Ipojuca (Barbosa et al. 2001) and Itamaracá (Favre 1999). Parasitological data for the municipalities of Jaboatão dos Guararapes, Itambé and Chã de Alegria had not been previously published. Only the data yielded by the baseline surveys (that is, prior to the treatment of carriers) carried out in these studies were considered in the present analysis.

Parasitological surveys for the diagnosis of S. mansoni infection were carried out by the Schistosomiasis
Reference Service of the Aggeu Magalhães Research Center-Fiocruz and employed a standardised methodology to map out each locality, register residents, collect faeces and conduct stool examinations (Favre 1999). The quantitative Kato-Katz method was used for parasitological diagnosis (Katz et al. 1972). Because the MS recommends that parasitological surveys be carried out with the use of one stool sample and the reading of a single Kato-Katz slide (MS 2007), the present study used only these results from the aforementioned studies.

Data processing - Information regarding age and the presence of S. mansoni eggs in the stool sample of each individual examined in the 19 localities were entered into an ACCESS database (Microsoft Office 2007, Microsoft Corporation, Redmond, WA, USA) and analysed using the statistical software package SYSTAT 11 (v.11; SYSTAT Software, Inc, Richmond, CA, USA). We used SYSTAT 11 to calculate the prevalence of infection, that is, the percentage of infected individuals in relation to those examined in the population as a whole and in the following age groups: $0-5,6-15,16-25,26-40$ and 41-80 years. The age group of 6-15 years, which is defined as "school-aged children" by WHO (2002), was adopted in this study since it is the age-range determined by law during which formal schooling occurs in Brazil.

For each locality, the prevalence of schistosomiasis in each age group was compared to that of the overall population. This was done using $2 \times 2$ contingency tables and the Chi-square test and/or Fisher's exact test as was appropriate for each analysis. In our analysis, the age groups whose prevalence of infection did not differ significantly (i.e., $p>0.05$ ) from that of the overall population were considered as potential reference groups. Pearson's correlation coefficient was calculated to evaluate the strength of the relationship between the prevalence for each age group and the overall prevalence in the locality using angular-transformed values (Sokal \& Rohlf 1995).

\section{RESULTS}

A total of 8,129 individuals were examined in the 19 localities, including 3,806 residents of the rainforest zone and 4,323 residents of the coastal zone. We tested $79.6 \%(8,129$ out of 10,211$)$ of the individuals in the communities included in this study. Population coverage ranged from $67.1 \%$ in Paroés to $100 \%$ in Pantanal, Merepe and Palheta. The average age ranged from 19.4 years in Araújo to 33.2 years in Chã de Aldeia (Table I). The proportion of school-aged children examined ranged from $17.9 \%$ in Merepe to $37.6 \%$ in Araújo.

Table II shows the prevalence of infection in the different age groups and in the overall population of the selected localities. The prevalence of schistosomiasis varied from $4.1 \%$ in Paroés to $63.8 \%$ in Araújo. An absence of schistosomiasis was only observed in the age groups of 0-5 years (Chã de Aldeia, Souto, Lagoinha, Palheta, Paroés and Bom Jesus), 26-40 years (Paroés) and 4180 years (Anil, Palheta and Paroés). In the locality of Paroés, the absence of infected people was observed in all three age groups above. In the locality of Anil, no children under the age of six were tested. 
TABLE I

Demographic data of the selected localities by municipality and physiographical zone

\begin{tabular}{|c|c|c|c|c|c|c|}
\hline $\begin{array}{c}\text { Physiographical } \\
\text { zone }\end{array}$ & Municipality & Locality & $\begin{array}{l}\text { Residents } \\
\text { (n) }\end{array}$ & $\begin{array}{l}\text { Examined } \\
\text { (n) }\end{array}$ & $\begin{array}{c}\text { Age } \\
(\text { mean } \pm \mathrm{SD})\end{array}$ & Survey \\
\hline \multirow[t]{13}{*}{ Rainforest zone } & \multirow{4}{*}{$\begin{array}{c}\text { São Lourenço } \\
\text { da Mata }\end{array}$} & Araújo & 181 & 149 & $19.4 \pm 14.9$ & 1997 \\
\hline & & Camorim & 462 & 417 & $21.5 \pm 17.7$ & 1995 \\
\hline & & Covas & 285 & 237 & $21.8 \pm 18.0$ & 1997 \\
\hline & & Poço Dantas & 216 & 184 & $21.7 \pm 16.2$ & 1997 \\
\hline & Itambé & Caricé & 1,882 & 1,532 & $27.5 \pm 19.2$ & 2004 \\
\hline & \multirow[t]{8}{*}{ Chã de Alegria } & Chã de Aldeia & 217 & 161 & $33.2 \pm 20.5$ & 2003 \\
\hline & & Souto & 127 & 103 & $27.1 \pm 20.6$ & 2003 \\
\hline & & Anil & 119 & 83 & $28.6 \pm 18.1$ & 2003 \\
\hline & & Brasil & 331 & 246 & $24.9 \pm 18.0$ & 2003 \\
\hline & & Lagoinha & 345 & 249 & $27.3 \pm 19.0$ & 2003 \\
\hline & & Palheta & 109 & 109 & $23.8 \pm 18.7$ & 2003 \\
\hline & & Paroés & 143 & 96 & $27.8 \pm 19.0$ & 2003 \\
\hline & & Bom Jesus & 356 & 240 & $27.5 \pm 19.9$ & 2003 \\
\hline \multirow[t]{6}{*}{ Coastal zone } & Itamaracá & Bom Jesus & 296 & 247 & $22.5 \pm 17.3$ & 1995 \\
\hline & Jaboatão dos Guararapes & Sotave & 3,330 & 2,271 & $26.4 \pm 17.7$ & 2003 \\
\hline & Ipojuca & Merepe & 251 & 251 & $29.6 \pm 18.6$ & 2000 \\
\hline & & Pantanal & 407 & 407 & $23.9 \pm 17.1$ & 2000 \\
\hline & & Salinas & 664 & 660 & $22.8 \pm 17.1$ & 2000 \\
\hline & & Socó & 490 & 487 & $22.4 \pm 16.9$ & 2000 \\
\hline
\end{tabular}

SD: standard deviation.

The highest prevalence of schistosomiasis occurred in the following age groups: 6-15, 16-25 and 26-40 years. The lowest prevalence (1.8\%) was observed in the 4180 year-old age group in Chã de Aldeia and the highest prevalence $(82.1 \%$ ) was observed in the $6-15$ year-old age group in Araújo. The results of the analysis that compared the prevalence of infection in each age group, and that of the population as a whole showed that in the age group of 0-5 years, infection prevalence did not differ significantly from that of the overall population in seven localities and was significantly lower than that of the overall population in the other 11 localities tested. In the locality of Anil, the analysis was not carried out because there were no children examined in this age group.

The prevalence of infection in the 41-80 year-old age group did not differ significantly from that of the overall population in 16 localities and, in the other three, it was significantly lower than that of the overall population. In the $6-15,16-25$ and $26-40$ year-old age groups, the prevalence of infection was not statistically different from that of the population as a whole in 17 , nine and 18 localities, respectively. In the 6-15 and 26-40 year-old age groups, infection prevalence was higher than that of the overall population in only two and one localities, respectively. On the other hand, in the 16-25 year-old age group, infection prevalence was significantly higher than that of the overall population in 10 of the 19 localities tested (Table II).
In those localities in which the prevalence of schistosomiasis prevalence was categorised as low (less than $10 \%$ according to WHO standards), the prevalence values in the various age groups did not differ significantly when each was compared to the prevalence value of the entire population in the respective locality. This occurred in four localities in the municipality of Chã de Alegria (Table II).

There was a positive correlation between the prevalence of infection in each age group and that of the overall population, as follows: $0-5$ years $(r=0.854), 6-15$ years $(r=0.967), 16-25$ years $(r=0.943), 26-40$ years $(r=0.934)$ and $41-80$ years $(r=0.884)$.

\section{DISCUSSION}

Selection of the reference group - Because the prevalence of infection among children between zero and five years of age tended to underestimate prevalence of infection of the population as a whole, children in this age group should not be used as a reference or target group in baseline surveys. These findings were expected because young children tend to have less contact with transmission foci as compared to individuals in the other age groups (Massara et al. 2004). In fact, 16 out of the 18 localities that were statistically evaluated revealed an infection prevalence of below $10 \%$ among children aged 0-5 years (Table II). Similarly, the 41-80 year-old age group may also be disregarded as a potential reference 
TABLE II

Prevalence of infection in the different age groups and in the entire population of the selected localities

\begin{tabular}{|c|c|c|c|c|c|c|}
\hline \multirow[b]{2}{*}{ Localities } & \multicolumn{5}{|c|}{ Age groups (years) } & \multirow[b]{2}{*}{$\begin{array}{c}\text { All ages } \\
(\%)\end{array}$} \\
\hline & $\begin{array}{l}0-5 \\
(\%)\end{array}$ & $\begin{array}{c}6-15 \\
(\%)\end{array}$ & $\begin{array}{c}16-25 \\
(\%)\end{array}$ & $\begin{array}{c}26-40 \\
(\%)\end{array}$ & $\begin{array}{c}41-80 \\
(\%)\end{array}$ & \\
\hline Araújo & $27.3^{a}$ & $82.1^{b}$ & $74.2^{c}$ & $62.5^{c}$ & $31.3^{a}$ & 63.8 \\
\hline Camorim & $5.5^{a}$ & $35.9^{c}$ & $45.7^{b}$ & $45.6^{c}$ & $30.3^{c}$ & 33.5 \\
\hline Covas & $5.7^{a}$ & $40.2^{c}$ & $45.9^{b}$ & $19.4^{c}$ & $19^{c}$ & 29.1 \\
\hline Poço Dantas & $4.5^{a}$ & $50^{c}$ & $66^{b}$ & $45.8^{c}$ & $50^{c}$ & 48.4 \\
\hline Caricé & $6.6^{a}$ & $48.7^{b}$ & $57.4^{b}$ & $42.4^{c}$ & $26.4^{a}$ & 39.8 \\
\hline Chã de Aldeia & $0^{c}$ & $10.5^{c}$ & $14.8^{c}$ & $2.9^{c}$ & $1.8^{c}$ & 6.2 \\
\hline Souto & $0^{c}$ & $26.3^{c}$ & $23.1^{c}$ & $15.4^{c}$ & $14.3^{c}$ & 16.5 \\
\hline Anil & ND & $9.5^{c}$ & $10^{c}$ & $15.4^{c}$ & $0^{c}$ & 8.4 \\
\hline Brasil & $10^{c}$ & $18.4^{c}$ & $21.3^{c}$ & $16.7^{c}$ & $5.7^{c}$ & 15.4 \\
\hline Lagoinha & $0^{c}$ & $9.3^{c}$ & $15.5^{c}$ & $15.9^{c}$ & $6.7^{c}$ & 10.8 \\
\hline Palheta & $0^{c}$ & $5.7^{c}$ & $47.1^{b}$ & $20.8^{c}$ & $0^{c}$ & 13.7 \\
\hline Paroés & $0^{c}$ & $4.2^{c}$ & $14.3^{c}$ & $0^{c}$ & $0^{c}$ & 4.1 \\
\hline Bom Jesus & $0^{c}$ & $3.8^{c}$ & $10^{c}$ & $10^{c}$ & $9.7^{c}$ & 7.5 \\
\hline Bom Jesus & $8.3^{a}$ & $49.2^{c}$ & $51.3^{c}$ & $35.1^{c}$ & $38.5^{c}$ & 40.2 \\
\hline Sotave & $4.8^{a}$ & $26.2^{c}$ & $36.1^{b}$ & $29.4^{b}$ & $18.1^{a}$ & 24.7 \\
\hline Merepe & $4.6^{a}$ & $31.1^{c}$ & $46.2^{b}$ & $37.5^{c}$ & $20.6^{c}$ & 30.8 \\
\hline Pantanal & $8.5^{a}$ & $55.3^{c}$ & $65.9^{b}$ & $58.4^{c}$ & $48.5^{c}$ & 50.4 \\
\hline Salinas & $3.4^{a}$ & $25^{c}$ & $30.7^{b}$ & $26.2^{c}$ & $17.3^{c}$ & 22.4 \\
\hline Socó & $5.8^{a}$ & $41.5^{c}$ & $47.6^{b}$ & $39.2^{c}$ & $25.4^{c}$ & 34.7 \\
\hline All localities & $5.7^{a}$ & $33.9^{b}$ & $41.8^{b}$ & $33.2^{b}$ & $20.8^{a}$ & 29.5 \\
\hline
\end{tabular}

$a$ : significantly lower; $b$ : significantly higher; $c$ : not significant; ND: no data.

group since the prevalence of infection in that age group underestimated that of the entire population in three localities and because in three localities there were no records of disease among individuals aged 41-80 years.

Because the prevalence observed in all age groups including individuals aged 6-40 years did not underestimated the prevalence of schistosomiasis in the overall population, any of them, in theory, could be chosen as a reference or target group for baseline surveys. Nevertheless, it should be noted that, in 10 localities, the prevalence in the 16-25 year-old age group overestimated the prevalence of infection in the overall population, which may compromise its choice as a reference group. For the choice of a reference group, it is important to consider prevalence as well as the operational difficulties involved in the successful completion of residential parasitological surveys in economically active age groups. According to the Brazilian Institute of Geography and Statistics, the economically active Brazilian population is concentrated among individuals aged 18-49 years, with over $90 \%$ of individuals in that age range having some sort of occupation. Therefore, residential stool collection may be hampered if most people in the selected target group spend all day, or even all week, away from their residences at their place of work. This may constitute a strong reason not to use the 26-40 year-old age group as the reference group, although, from the point of view of the comparative analysis adopted in this study, the infection prevalence in this age group was found to be an adequate indicator of the prevalence of infection in the community.

On the other hand, the age group including children aged 6-15 years, in addition to being adequate from the point of view of the comparative analysis of prevalence (in fact, infection prevalence in this age group demonstrated the highest positive correlation with overall population prevalence), displays several characteristics that make it adequate both as reference and target group. These characteristics include the following: (i) it is the age range established by law for formal schooling in Brazil, which implies compulsory enrollment in elementary schools, (ii) schoolchildren and their families are generally accessible and receptive to this type of testing, (iii) children in this age group are the main targets of WHA-54.19, whose member countries, including Brazil, committed to the minimum goal of providing diagnostic coverage and treatment for helminth infection to $75 \%$ of school-aged children in endemic areas by the year 2010 (WHO 2002), (iv) data collected from individuals in this age range may be used to evaluate not only the health threat of schistosomiasis to schoolchildren, but also the need for intervention in the community as a whole (Montresor et al. 2002), (v) the school infrastructure reduces the operational costs for parasitological surveys and medication administration because it concentrates activities in a specific physical space and, in addition, provides an excellent opportunity to reach non-enrolled children (Favre et al. 2009), (vi) targeting intermediate grade-level children (generally between 


\section{TABLE III}

Schistosomiasis control strategy for endemic municipalities taking into account the classes of prevalence of the population and the infrastructure of the Basic Attention/Family Health (AB/SF) teams

\begin{tabular}{|c|c|c|c|}
\hline Classes of prevalence ${ }^{a}$ & Infrastructure $^{b}$ & Actions in schools & Actions in communities \\
\hline \multirow{2}{*}{$\begin{array}{l}\text { Moderate to high } \\
(>10 \%)\end{array}$} & Unsatisfactory & $\begin{array}{l}\text { Stool survey of all schoolchildren } \\
\text { and treatment of the positives. } \\
\text { Health education. }\end{array}$ & $\begin{array}{c}\text { Case detection and investigation } \\
\text { by the } \mathrm{AB} / \mathrm{SF} \text { teams. }\end{array}$ \\
\hline & Satisfactory & Health education. & $\begin{array}{l}\text { Active search and treatment of } \\
\text { positives by the AB/SF teams. }\end{array}$ \\
\hline \multirow[t]{2}{*}{$\begin{array}{l}\text { Low } \\
\text { (up to } 10 \% \text { ) }\end{array}$} & Unsatisfactory & $\begin{array}{l}\text { Stool survey of all schoolchildren } \\
\text { and treatment of the positives at entry } \\
\text { (1st grade) and at exit (9th grade). } \\
\text { Health education. }\end{array}$ & \multirow[t]{2}{*}{$\begin{array}{c}\text { Case detection and investigation by } \\
\text { the } \mathrm{AB} / \mathrm{SF} \text { teams. }\end{array}$} \\
\hline & Satisfactory & Health education. & \\
\hline
\end{tabular}

$a$ : based on recent, reliable estimates; $b$ : material and human resources required to attend the activities of the Schistosomiasis Control Program.

9-12 years of age) allows for the follow-up of the impact of treatment over the period of one or two years before they leave school, (vii) the school environment allows for the discussion of various issues related to schistosomiasis and other important threats in the community, promoting more ample debate on disease prevention and control among schoolchildren, families and health agents (Schall 1994), (viii) schoolchildren who were tested positive serve as a good indicator that could lead to the identification of infected family members, including non-enrolled children (Massara et al. 2006, Enk et al. 2008), (ix) a study conducted in the endemic area of Minas Gerais, Brazil, validated the use of prevalence among individuals in the 7-14 year-old age group to predict $S$. mansoni prevalence in the community, confirming that it can be used to guide treatment strategies in the endemic area (Rodrigues et al. 2000) and (x) this age group has already been targeted in control campaigns carried out by the MS in the 1970's and 1980's, which attests its importance not only as a group that is particularly vulnerable to infection, but also as an important source of information regarding environmental contamination.

Estimates of the current prevalence of schistosomiasis from school surveys - Because the 6-15 year-old age group was found to be adequate both as a reference and a target group from the parasitological as well as the operational viewpoint, a scheme for carrying out baseline and follow-up surveys in this age group may be proposed based on the following assumptions: (i) reliable estimates regarding prevalence of infection in a locality, municipality or endemic area can be obtained from school parasitological surveys (Montresor et al. 1998, 2002, WHO 2002), (ii) school surveys using reliable sampling techniques can be incorporated into the routine activities of the PCE-SUS (Barbosa et al. 2006, Favre et al. 2006b) and (iii) the AB/SF actions may not be limited to the UBS, as there have been recommen- dations made to carry out these actions in community spaces such as schools (MS 2007).

The main goal of this scheme is to assist the municipalities that do not possess the resources to follow the current recommendations of the SVS-MS for the diagnosis and treatment of schistosomiasis. It also seeks to adapt the recent recommendations of the WHO (WHO 2002) to the situation present in Brazil by combining the actions of local healthcare entities with those targeting school-aged children. An ample coverage of elementary school students, complemented by active search for nonenrolled children living in the neighbourhood, would most likely suffice to allow the attainment of the minimum goal of the WHA-54.19 of providing coverage to $75 \%$ of school-aged children (Favre et al. 2006a).

To conduct a baseline survey in a specific municipality, a representative sampling of elementary schoolchildren may be chosen to reflect the prevalence of disease in that municipality. This type of survey allows for the categorisation of the municipality into infection prevalence classes and the establishment of an infection-control strategy to be subsequently implemented (Montresor et al. 1998).

Selection of a control strategy - Once a municipality is categorised into one of the prevalence classes, local conditions of infrastructure that may threaten the implementation of control actions must be identified. Therefore, if the AB/SF teams in the municipality are well-structured and operational, their actions may reach the entire population. Thus, by carrying out population parasitological surveys and treating infected individuals through the UBS, the directive requirements of the SVSMS will be fulfilled. On the other hand, if the AB/SF teams are unable to assist the population as a whole, this approach will allow that municipality to at least reach the minimum goal of the WHA-54.19 of providing coverage to $75 \%$ of schoolchildren against schistosomiasis through school actions (Table III). 
Monitoring treatment impact - A follow-up school survey should be carried out two years after treatment to evaluate its impact. If this post-treatment survey reveals a prevalence of below $10 \%$ among schoolchildren, the municipality will then be considered a lowprevalence area. While this condition lasts, the recommendation is that schoolchildren be examined twice during elementary school; once during first grade and once during the final grade (WHO 2002).

One of the recent recommendations of the WHO regarding the control of schistosomiasis and other helminthic diseases emphasises that school actions may be coordinated with existing interventional programs (WHO 2005). The SUS itself could strengthen its responsibilities within the community at the level of basic health care by making use of the school setting (Pieri \& Favre 2007). As advocated by the politics of $A B$, the $A B / S F$ teams should seek partnerships and joint actions that could lead to the improvement of community health conditions (MS 2007). The initiative to promote integration between educational and health activities may bring countless benefits to the quality of life of families in the community. The school setting has a great power of articulation that, combined with the expertise of professionals from $\mathrm{AB} / \mathrm{SF}$ (including community health agents) and with effective community participation, may contribute to the development of methods to confront existing challenges.

In this context, the recently implemented School Health Program (Presidência da República 2007) could foreseeably include surveillance and control activities aimed at schistosomiasis and other helminthic infections by joining the efforts of the health and education teams in the school setting to complement their actions at the community level (Favre et al. 2009). Thus, teachers and other school staff can act as facilitators to encourage children to participate in parasitological surveys and treatment and to encourage the adoption of healthy habits and preventive measures by the children and their families. By taking part in health education actions, the school contributes to the improvement of the well-being, childhood development, academic achievement, self-esteem and self-confidence of its students and to the decrease in rates of school abandonment, absenteeism and grade repetition. These actions clearly have favourable repercussions in the community as a whole.

\section{REFERENCES}

Barbosa CS, Domingues AL, Abath F, Montenegro SM, Guida U, Carneiro J, Tabosa B, Moraes CN, Spinelli V 2001. Epidemia de esquistossomose aguda na praia de Porto de Galinhas, Pernambuco, Brasil. Cad Saude Publica 17: 725-728.

Barbosa CS, Favre TC, Wanderley TN, Callou AC, Pieri OS 2006. Assessment of schistosomiasis, through school surveys, in the forest zone of Pernambuco, Brazil. Mem Inst Oswaldo Cruz 101 (Suppl. I): 55-62.

Beck L, Favre TC, Pieri OS, Zani LC, Domas GG, Barbosa CS 2001. Replacing oxamniquine by praziquantel against Schistosoma mansoni infection in a rural community from the sugar-cane zone of Northeast Brazil: an epidemiological follow-up. Mem Inst Oswaldo Cruz 96 (Suppl.): 165-167.

Coura JR, Amaral RS 2004. Epidemiological and control aspects of schistosomiasis in Brazilian endemic areas. Mem Inst Oswaldo Cruz 99 (Suppl. I): 13-19.

Enk MJ, Lima AC, Massara CL, Coelho PM, Schall VT 2008. A combined strategy to improve the control of Schistosoma mansoni in areas of low prevalence in Brazil. Am J Trop Med Hyg 78: 140-146.

Favre TC 1999. Impacto da quimioterapia com oxamniquine sobre a infecção por Schistosoma mansoni em duas localidades da zona litoral-mata de Pernambuco, $\mathrm{PhD}$ Thesis, Fundação Oswaldo Cruz, Rio de Janeiro, 148 pp.

Favre TC, Pereira AP, Galvão AF, Zani LC, Barbosa CS, Pieri OS 2009. A rationale for schistosomiasis control in elementary schools of the rainforest zone of Pernambuco, Brazil. PLoS Negl Trop Dis 3: e395.

Favre TC, Pieri OS, Barbosa CS 2007. Aspectos malacológicos e epidemiológicos envolvidos na transmissão da esquistossomose em Pernambuco. In SB dos Santos, RS Absalão (eds.), Tópicos em malacologia brasileira - Ecos do XVIII Encontro Brasileiro de Malacologia, Sociedade Brasileira de Malacologia, Rio de Janeiro, p. 267-276.

Favre TC, Ximenes RA, Galvão AF, Pereira AP, Wandereley TN, Barbosa CS, Pieri OS 2006a. Attaining the minimum target of resolution WHA 54.19 for schistosomiasis control in the rainforest zone of the state of Pernambuco, Northeastern Brazil. Mem Inst Oswaldo Cruz 101 (Suppl. I): 125-132.

Favre TC, Ximenes RA, Galvão AF, Pereira AP, Wanderlei TN, Barbosa CS, Pieri OS 2006b. Reliability of current estimates of schistosomiasis prevalence in the rainforest zone of the state of Pernambuco, Northeastern Brazil. Mem Inst Oswaldo Cruz 101 (Suppl. I): 73-78.

Katz N, Chaves A, Pellegrino J 1972. A simple device for quantitative stool thick-smear technique in schistosomiasis mansoni. Rev Inst Med Trop Sao Paulo 14: 397-400.

Massara CL, Peixoto SV, Barros HS, Enk MJ, Carvalho OS, Schall V 2004. Factors associated with schistosomiasis mansoni in a population from the municipality of Jaboticatubas, state of Minas Gerais, Brazil. Mem Inst Oswaldo Cruz 99 (Suppl. I): $127-134$.

Massara CL, Peixoto SV, Enk MJ, Barros HS, Carvalho OS, Sakurai E, Schall V 2006. Evaluation of an improved approach using residences of schistosomiasis-positive school children to identify carriers in an area of low endemicity. Am J Trop Med Hyg 74: 495-499.

Montresor A, Crompton DWT, Bundy DAP, Hall A, Savioli L 1998. Guidelines for the evaluation of soil-transmitted helminthiasis and schistosomiasis at community level. A guide for managers of control programmes, World Health Organization, Geneva, 45 pp.

Montresor A, Crompton DWT, Gyorkos TW, Saviolli L 2002. Helminth control in school-age children: a guide for managers of control programmes, World Health Organization, Geneva, 73 pp.

MS - Ministério da Saúde/Secretaria de Atenção à Saúde/Departamento de Atenção Básica 2007. Vigilância em saúde: dengue, esquistossomose, hanseníase, malária, tracoma e tuberculose, Cadernos de Atenção Básica, Série A, Normas e Manuais Técnicos 21, MS, Brasília, 199 pp. 
MS - Ministério da Saúde/Secretaria de Vigilância em Saúde 2008. Programa de Controle da Esquistossomose. Departamento de Informática do Sistema Único de Saúde - Datasus. [cited 2009 Jan 12]. Available from: http://tabnet.datasus.gov.br/cgi/ deftohtm.exe?sinan/pce/cnv/pce.def.

Pieri OS, Favre TC 2007. Incrementando o Programa de Controle da Esquistossomose. Cad Saude Publica 23: 1733-1734.

Presidência da República Federativa do Brasil 2007. Legislação. Decretos. [cited 2009 Jan 12]. Avaliable from: http://www.planalto. gov.br/ccivil_03/_ato2007-2010/2007/decreto/d6286.htm.

Rodrigues LC, Wheeler JG, Shier R, Guerra HL, Pimenta F Jr, Lima e Costa MF 2000. Predicting the community prevalence of schistosomiasis mansoni from the prevalence among 7- to 14-year-olds. Parasitology 121: 507-512.

Schall VT 1994. Environmental and health education for school- age children: a transdisciplinary approach. Cad Saude Publica 10: $259-263$.

Sokal RP, Rohlf JF 1995. Biometry: the principles and practice of statistics in biological research, 3rd ed., WH Freeman \& Co, New York, 887 pp.

WHO - World Health Organization 2002. Prevention and control of schistosomiasis and the soil-transmitted helminthiasis. Report of a WHO Expert Committee, WHO, Geneva, 73 pp.

WHO - World Health Organization 2005. Report of the third global meeting of the partners for parasite control. Deworming for Health and Development, WHO, Geneva, $51 \mathrm{pp}$.

Zani LC, Favre TC, Pieri OS, Barbosa CS 2004. Impact of antihelminthic treatment on infection by Ascaris lumbricoides, Trichuris trichiura and hookworms in Covas, a rural community of Pernambuco, Brazil. Rev Inst Med Trop Sao Paulo 46: 63-71. 